\title{
Understanding dental wear
}

\author{
Emmanuel d'INCAU, Paul SAULUE
}

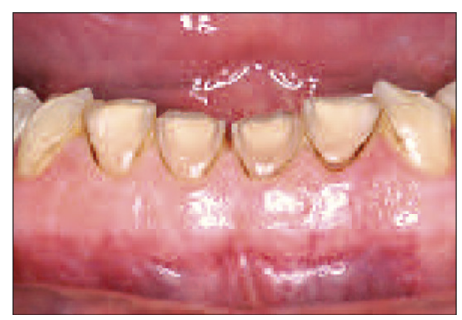

\begin{abstract}
Dental wear is deterioration as a result of use. It has existed since the beginning of mankind in all civilizations and cultures. It occurred routinely and intensely in early populations but was considered to be a physiological process. Ideas about dental wear are not as clear today because while it is less pronounced it sometimes appears in pathological patterns. Moreover, it is produced by many complex mechanisms acting in synchrony or sequentially, in synergy or additive, in patterns that often mask its true origins. In an effort to ameliorate the means of preventing and diagnosing dental wear and improving our understanding of its diverse manifestations, the primary objective of this article will be to present the principal mechanisms that produce it as well as their consequences. To organize our presentation we have adopted a tribological approach, focusing on the friction, wear, and lubrication of interacting surfaces.
\end{abstract}

\section{KEY WORDS}

Dental wear,

Oral tribology,

Attrition,

Abrasion,

Erosion.

Wear is deterioration as a result of use. Occurring in teeth, it is considered to be a physiological and adaptive phenomenon that has existed since the beginning of mankind. This notion is sometimes confusing because wear can also assume a pathological character when it is associated with problems of alimentation, bruxism with frequent awakenings from sleep, noxious habits, medications, or certain types of behavior or repeated work-controlled activity. So wear may be produced by many complex mechanisms, acting in synchrony or sequentially, in synergy or additive, in patterns that often mask its true origins. Accordingly, in order to ameliorate the diagnosis and prevention of dental wear, the primary objective of this article is to 
present the fundamental tribological mechanisms that cause it as well as the principal consequences its development has on the masticatory system. We shall make certain recommendations that dentists can use in the management of wear to reduce its deleterious effects.

\section{1 - DEFINITION OF TRIBOLOGY}

Wear is a generic term commonly used in dentistry to describe the phenomenon of attrition that occurs when two dental surfaces, occlusal to occlusal or proximal against proximal, rub against each other; abrasion caused by action of rough elements of foodstuffs during mastication; by excessively vigorous tooth brushing; and by erosion from chemical dissolution. Despite its widespread acceptance the term wear that John Hunter, the Scottish anatomist, surgeon, and dental scientist introduced 1798, does not perfectly reflect the variety of physical and chemical mechanisms that produce it. Moreover, it seems to suggest that the three causative factors operate separately when, more frequently, they interact, making clinical diagnosis more difficult $3,19,28,37,38$. Another, more scientific, approach would be to utilize terms borrowed from the science of tribology, a division of the field of mechanical engineering ${ }^{29,54-55}$. This science and technology encompasses the study of friction, wear, and lubrication. In order to acquire a better understanding of the fundamental mechanisms of dental wear and of restorative materials, dentists should think of the oral cavity as participating in a tribolo-

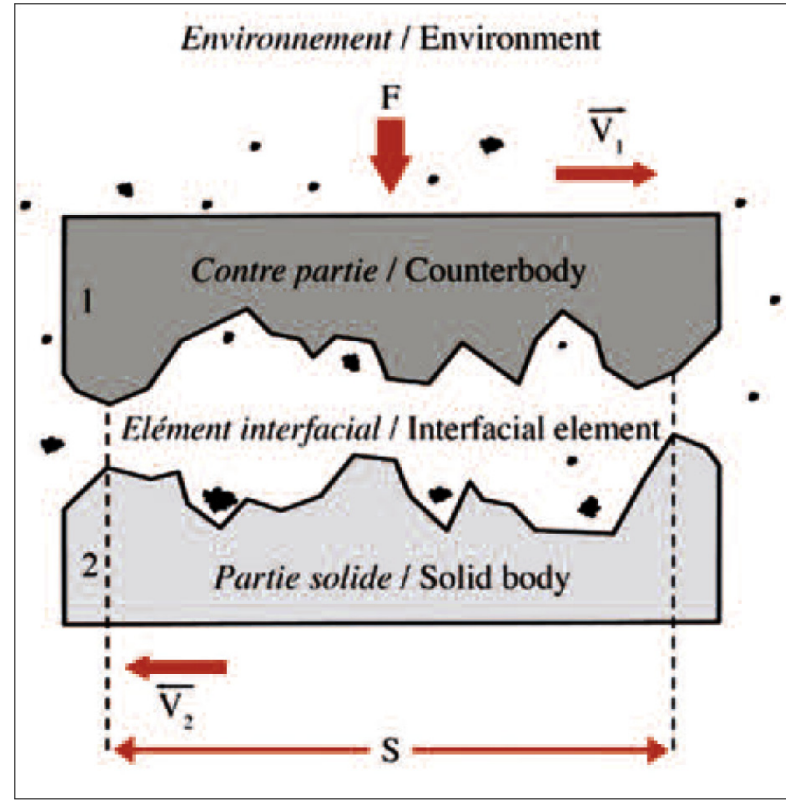

Figure 1

A schematic representation of a tribo-system. The two solids, 1 and 2, moving at speeds Vi and V2 are pressed against each other by force $F$. These solids are in contact with surface $S$ and subject to a contact pressure $p=F / S$, the Pascal unit.

gical system composed of four elements $^{56}$ (fig. 1):

- A solid body, represented by a tooth, in its original state or restored;

- A counter body, represented most frequently by another opposing solid such as an antagonistic tooth or a soft tissue, the tongue; more rarely by a liquid, a gas, or a combination of these different elements;

- an eventual inter-surface unit represented by a solid like a hard particle contained in a bolus of food or a dentifrice; a liquid of varying degrees of lubricity like saliva, more 
rarely a gas, or a combination of the two;

- an environment most often represented by surrounding air.

Within this system four fundamental wear mechanisms can be described and applied to dental tissues as well as to restorative materials ${ }^{35}$.

\section{2 - ABRASIVE WEAR}

Examined under a microscope no surface appears totally smooth. When two different surfaces meet it is their asperities that come into contact acting as abrasive particles. According to the micro-rugosities of these materials micro-contacts of varying dimensions establish themselves defining an effective surface much less extensive than its macro-dimensions would suggest. In addition, even if the global pressure exerted between the two materials is weak, the local pressure expressed between micro-contacts is sometimes so great that it can deform or even rupture them. Depending upon the number of materials in contact tribology distinguishes two types of abrasive wear: two-body abrasion and three-body abrasion.

\section{2 - 1 - Abrasion between two bodies}

This is the type of abrasion of two solid moving bodies whose surfaces are in direct contact. In odontology it is often called attrition, which can cause confusion.

Tribology distinguishes four models of abrasion whose type of contact depends on the angle of attack and

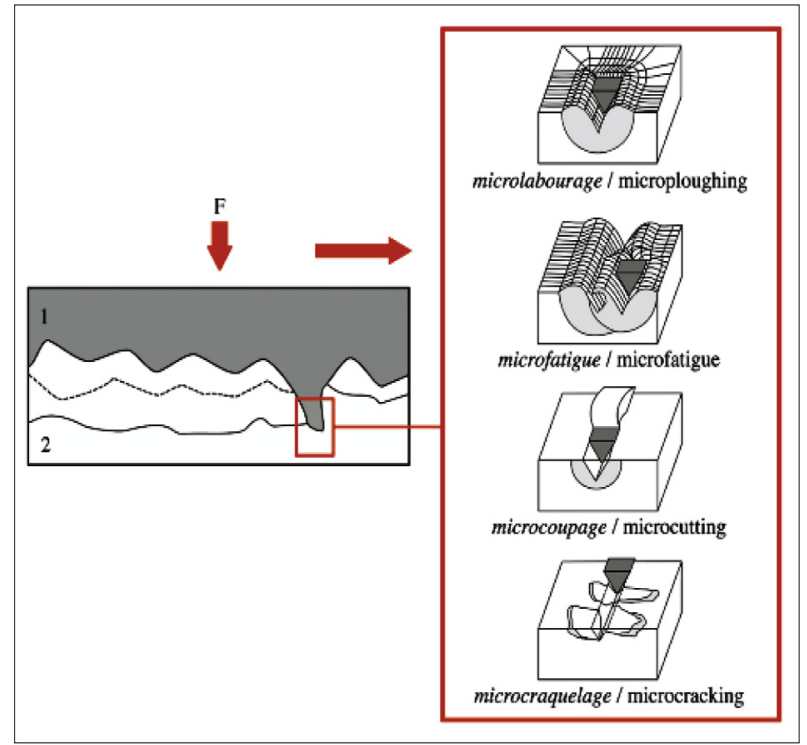

Figure 2

Different models of wear between two bodies lafter Zum Gahr KH. Wear by hard particles. Tribology Int 1998; 31(10):587-96).

the angle of the asperities, on the coefficient of friction, the speed of movement, the pressure, the distance and the hardness differential between two contacting surfaces ${ }^{2,57}$ (fig. 2):

- When the hardness of two surfaces, like enamel and dentin, are quite different, the asperities of the harder surface dig into the more ductile surface in accordance with the behavior of a mechanism called microploughing. Microscopically a plow is formed before each moving abrasive particle creating a principal furrow with symmetrical lateral borders. These grooves continue to form parallel to the direction of the movement of the abrasive particles. Their proximity ends up by weakening the more ductile material, deforming it locally and removing some of its substance through a process known as microfatigue. 
- When two breakable materials with similar elevated degrees of hardness such as highly hardened metal and ceramics come into contact the micro-asperities of the harder material slice cleanly through the more ductile material without causing plastic distortion of its surface in a process called microcutting. The shape and the volume of the grooves thus produced correspond exactly to the volume of the material plowed away. If the two surfaces are, in addition, subjected to strong pressure, some surface asperities can become detached in a process called microcracking. Small fissures then form along the entirety of a major groove, propagating themselves and then uniting in blocks of the two materials that can become detached.

With a repetition of these passages all asperities are subjected to one or more of these models and separate so greatly from their bases that the cumulative effect of these microscopic losses becomes macroscopic, visible wear.

In the oral cavity these progressive phenomena cause tooth-to-tooth friction interproximally and occlusally that can be physiological or pathological.

The proximal abrasion between two dental surfaces is related essentially to the cumulative effect of masticatory forces. Two factors acting together are responsible. The first is a bucco-lingual lateral movement that occurs within the limits imposed by the visco-elasticity of periodontal membranes. The second is the postero-anterior force that derives from the ensemble of occlusal pressures exerted on the two arches thrusting

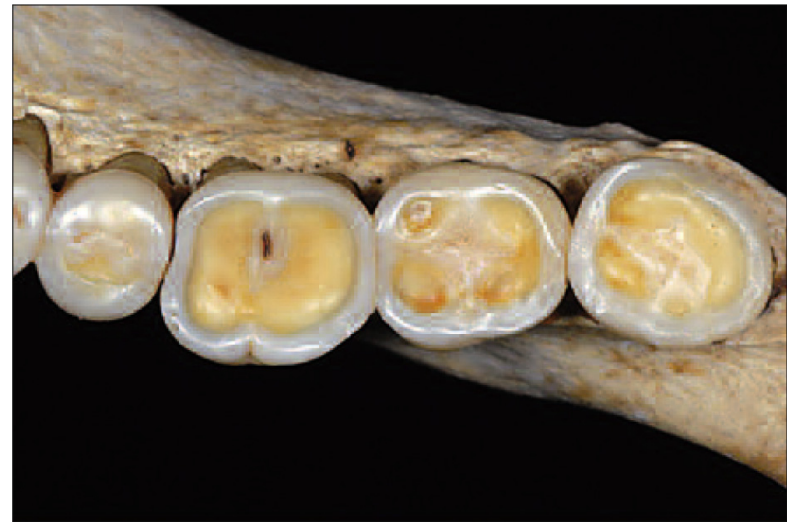

Figure 3

Wear of attrition reshaped the teeth of Stone Age man to a considerable degree. Because of the resultant mesial drift of teeth arch length was markedly reduced. (Coll. Sains-en-Gohelle, 7-15 s.)

distal teeth against the teeth mesial to them ${ }^{49}$. The periodontal membrane's capacity of being depressed axially when a tooth is subjected to occlusal force must be added to these two factors. The marked interproximal wear that characterized the dentitions of primitive man (fig. 3) led to progressive mesial drift of teeth and a consequent reduction in the length of dental arches ${ }^{8}$. The same adaptation of attrition still occurs in contemporary industrialized populations but at a greatly reduced rate. Contact points between teeth, originally just that, a single contact, evolve physiologically with age into contact surfaces that dentists must be careful to respect and reproduce in all reparative dental techniques. In certain rare pathological circumstances some individuals suffer from such severe waking or night time bruxism that discrete enamel chips break off from occlusal or proximal surfaces. But this is exceptional, because the mandibular kinematics of mastication are different from the 
movements occurring in episodes of grinding or clenching of teeth.

The abrasion that takes place between two bodies in the oral cavity is physiological when it is sparse. It is primarily related to swallowing and some inconstant masticatory contacts. Dentitions with considerable wear are characterized by wear facets that are smooth, shiny, and delimited by sharp angles (fig. 4). Posterior cusps and incisal edges of anterior teeth are flattened out. When dentin is

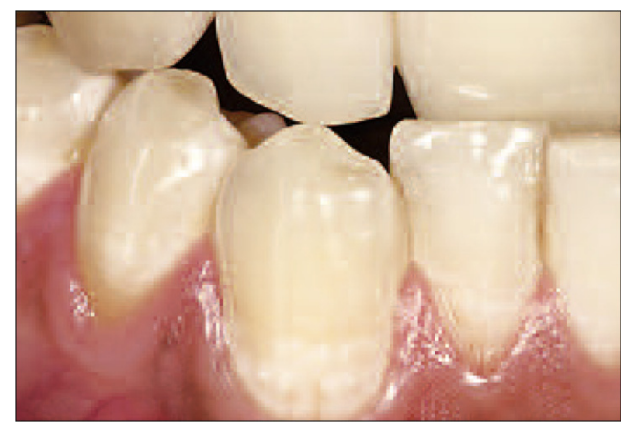

Figure 4

Wear of attrition is characterized by facets that are smooth, shiny, and delimited by sharp angles. This 28 year-old male patient was a bruxer during waking hours. exposed it appears at the same level as remaining enamel without any margin between them (fig. 5). In areas where wear is localized to hard dental tissue or restorations on antagonistic teeth, facets oppose each other and remain in contact during moderate excursive movements of the mandible. This characteristic is a basic condition for establishment of a diagnosis of a wear mechanism ${ }^{32}$, notably in patients with grinding or clenching behavior $^{42}$ (fig. 6 a to c). But in cases

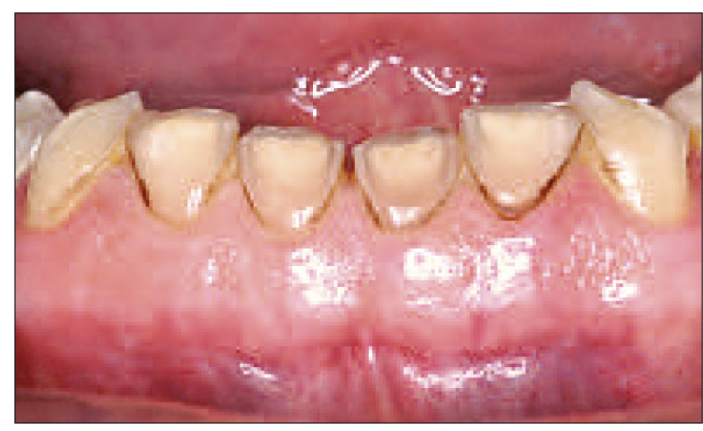

Figure 5

When wear is widespread throughout the dentition and dentin is exposed there is no demarcation between dentin and enamel. This 63 year-old patient was afflicted with sleep bruxism.

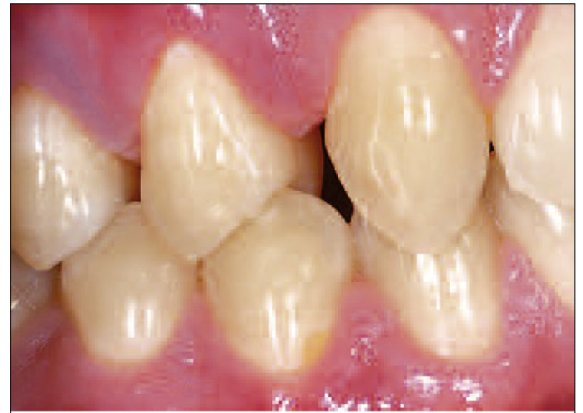

a

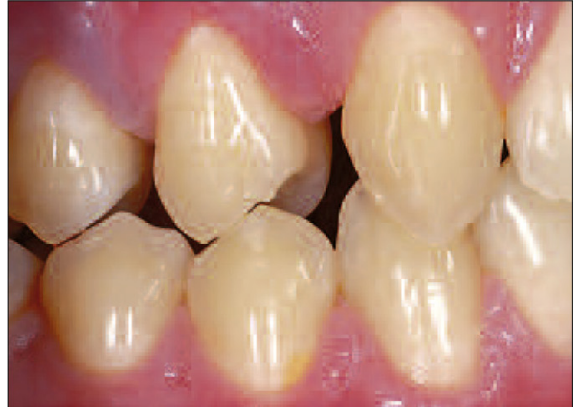

b

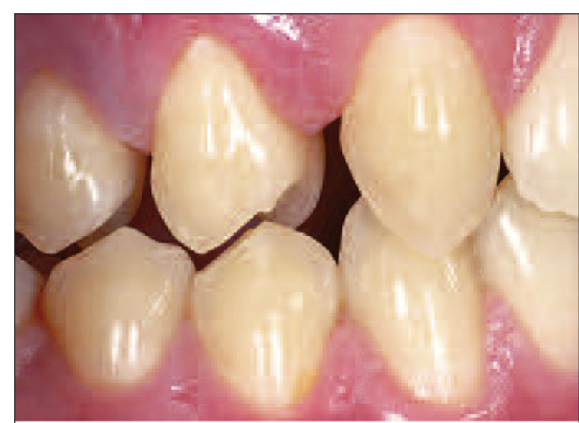

Figures 6 a to $c$

The attrition wear facets in this 24 year-old patient's two arches that correspond with each other and remain in contact during minor excursive movements of the mandible indicate to the examiner that a diagnosis of daytime bruxism is appropriate. In right excursion the canines are in firm contact. 
where surfaces do not correspond exactly between the arches or if wear is more advanced in one arch than it is in the other, examining dentists should conclude that one or more additional mechanisms are operating and must endeavor to find them ${ }^{5}$. One possible factor might be localized acid dissolution of dental tissues, designated as erosion in odontological terms, or abrasion by intervention of a third hard body carried in an abrasive diet operating on masticating teeth. Differential diagnosis is often difficult, but examiners should remember that many individuals interpose a variety of exterior substances between their teeth to play with or to chew on. These include fingernails, pins, tufts of hair, pipes and many other objects that are used in distinctive fashion to produce a mechanism of two-body wear. When these intruding bodies are withdrawn the opposing contacting surfaces of the antagonistic teeth no longer interact with each other.

Occlusally, pathological two-body abrasion is most frequently associated with noxious waking habits or nighttime bruxism and sometimes reaches spectacular levels (fig. 7 a to c). But presence of this type of wear does not automatically justify a diagnosis of the malady of bruxism ${ }^{11}$. A lowering of the quantity and quality of saliva can, for example, set off extensive occlusal wear by permitting acid to attack tooth surfaces or the resistance level of those surfaces may be reduced, especially in children. And adults who are clearly victims of bruxism do not always show clear signs of wear ${ }^{1}$. But in all cases, and no matter what its etiology may be, when wear is pathological, examiners must make an assessment of its kinetics a high priority. After taking an in depth anamnesis, dentists should include models and photographs in their record taking not only to help them evaluate the situation but also for use in explaining the nature of the phenomenon to patients and showing them how to alter their behavior in order to deal with it.

\section{2 - 2 - Three-body type of abrasion}

This phenomenon, which consists of two bodies moving against each

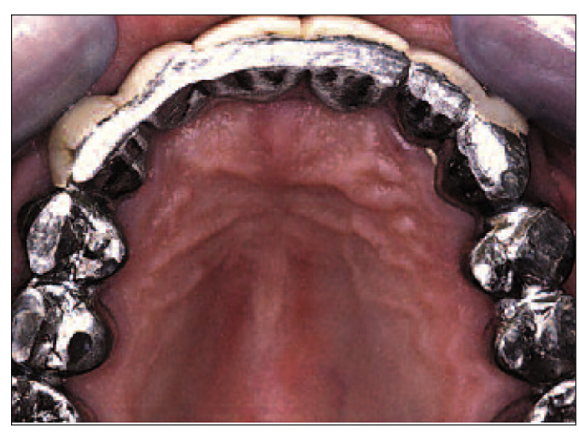

a

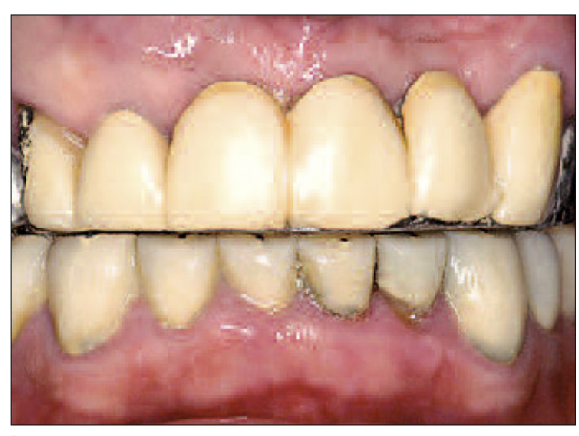

b

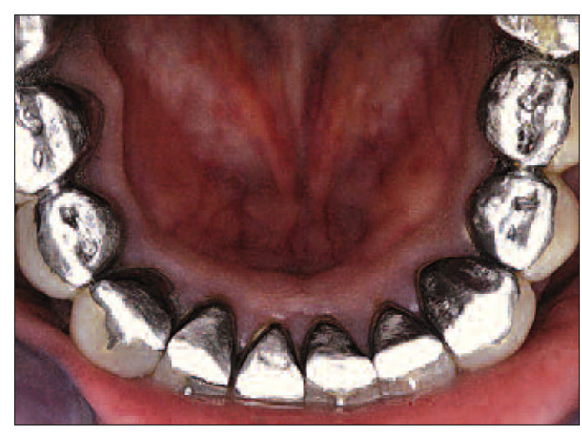

C

Figures 7 a to $c$

Severe attrition wear of a 55 year-old patient resulting from bruxism. In the anterior view the high hardness metal is at the same level as the covering cosmetic covering material. 


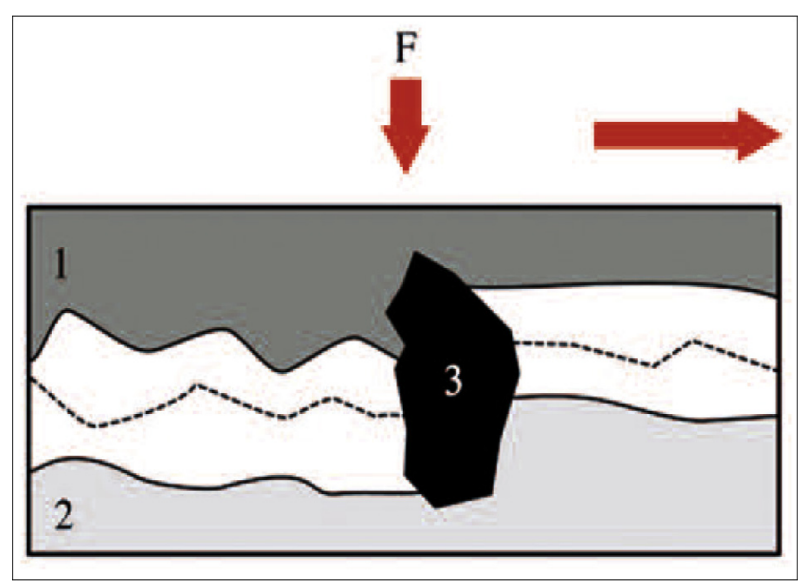

Figure 8

A schematic representation of three-body abrasion.

other with abrasive particles interposed between them constituting the third body (fig. 8). In odontology it is referred to simply as abrasion. Its severity depends, essentially, on the size, the shape, and the hardness of the intervening particles. In the field of tribology, two models of three-body abrasion are postulated as a function of the distance that separates the two major sliding bodies ${ }^{34}$ (fig. 9):

- When the two bodies are relatively far apart, the intervening particles are free to disperse themselves and behave like an overall abrasive suspension embracing the entirety of the two surfaces. Only a small proportion of the particles actively participate in attacking the two major bodies, which do not abrade in correspondence with each other because they are never in contact.

- When the two bodies move sufficiently close to each other, the abrasive particles are progressively entrapped and fall out of suspension. Then they are carried along by

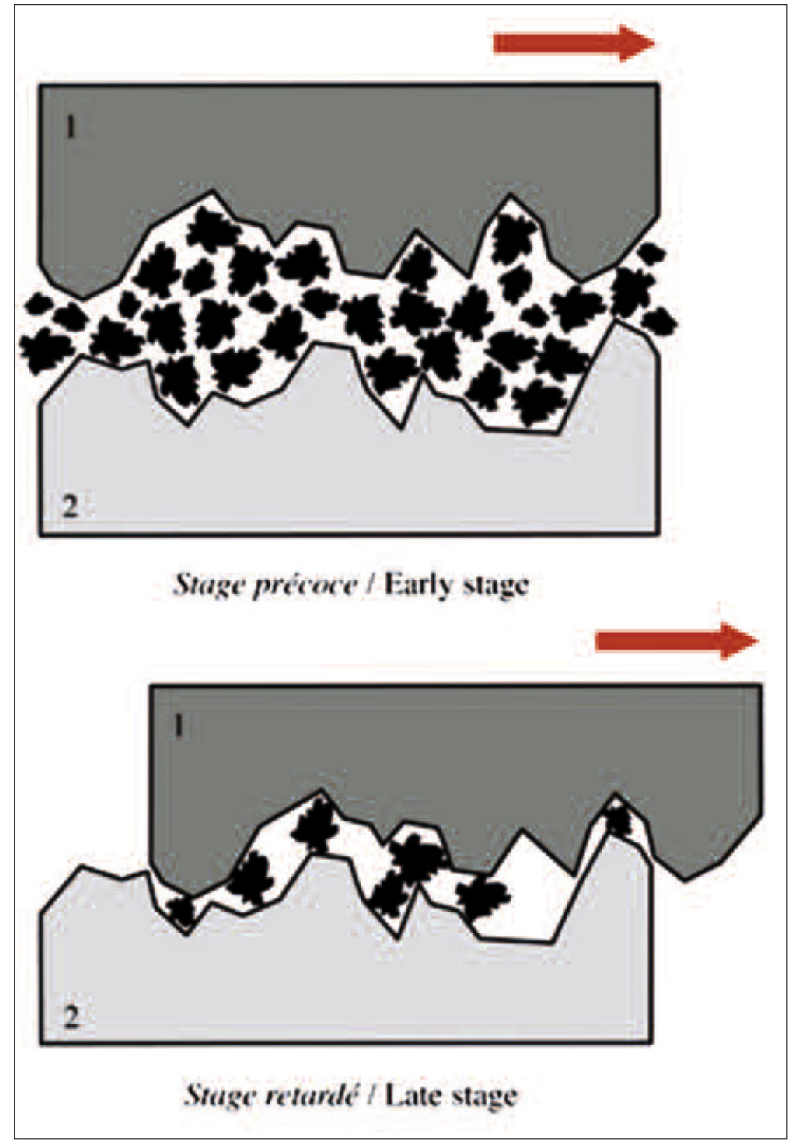

Figure 9

When two bodies are relatively far apart interstitial abrasive particles move about freely without causing much wear of the bodies. But when these bodies grow closer together the particles are entrapped in rough spots on the surfaces of one or both of the bodies, causing attrition (after Mair LH. Understanding wear in dentistry. Compend Contin Educ Dent 1999;20(1):19-30).

the two moving bodies creating specific grooves and fissures in them. Surfaces subjected to this type of wear sometimes develop corresponding characteristics because the particles have become integrated into the surfaces of the two sliding bodies and the wear then approximates the two-body model. 
In the oral cavity, three-body abrasion can be generalized and/or focused. When it is generalized it is usually associated with the abrasive contents of a bolus of food that affects the totality of tooth surfaces participating in mastication. During this activity, two phases take place successively in accordance with tribological models. Their activity occurs in function of the proximity of antagonistic teeth and the progressive dilaceration of the bolus of food $^{14}$.

- During a primary phase of crushing, the particles in the food become free to distribute themselves and to begin the process of abrasion preferably on occlusal surfaces that are not in contact with antagonistic teeth. On buccal and lingual tooth surfaces not covered by bacterial plaque, friction from the tongue and other soft tissues also contributes to the development of this wear, which is particularly visible on restorative materials such as composites ${ }^{27,45}$ or glass ionomer cements ${ }^{33}$ where abrasion of matrices eventually loosens the fillings;

- During a second phase of these two sliding surfaces in near contact, teeth of the opposing jaws move closer and closer to each other as the dilaceration of the bolus of food progressively entraps the particles into lacerations in the two body surfaces where they form microscopic pits and fissures characteristic of masticatory cycles and of masticated foods ${ }^{13}$. The rougher tooth surfaces or restorative materials become the more the abrasive particles tend to be incorporated into the surface micro-grooves. During this rapid and irregular stage of mastication tooth to tooth relationships become more intimate in broad occlusal contact regions that are then subjected to close twobody abrasion. Simultaneously the particles that are trapped on the tooth surfaces execute three-body abrasion in the occlusal areas where upper and lower teeth are no longer in intimate contact, continuing to operate during swallowing and even after in movements of auto-cleansing of the dentition and the oral cavity.

The cumulative effect of this process produces enamel surfaces that are flattened and glossy with rounded edges. When dentin is frankly exposed its relative structural weakness and high organic content result in a type of wear that is different from that of ename ${ }^{53}$. A clear delineation appears at the border between dentin and enamel because the softer dentin wears down more quickly and these dentin areas assume a concave form and yellowish brown coloration. The differential diagnosis of occlusal erosive lesions can sometimes be difficult. The three-body type of erosion that occurs primarily during mastication is sometimes called "demastication". It occurred universally in primitive populatons $^{22}$ (fig. 10). For these people opposing teeth of the two jaws acted against each other along with foodstuffs that were not necessarily abrasive in themselves but were often packed with extraneous particles, charcoal for example, that were harder than the teeth. As a result the masticatory systems of primitive man made certain adjustments including remodeling of the TMJ, continu- 


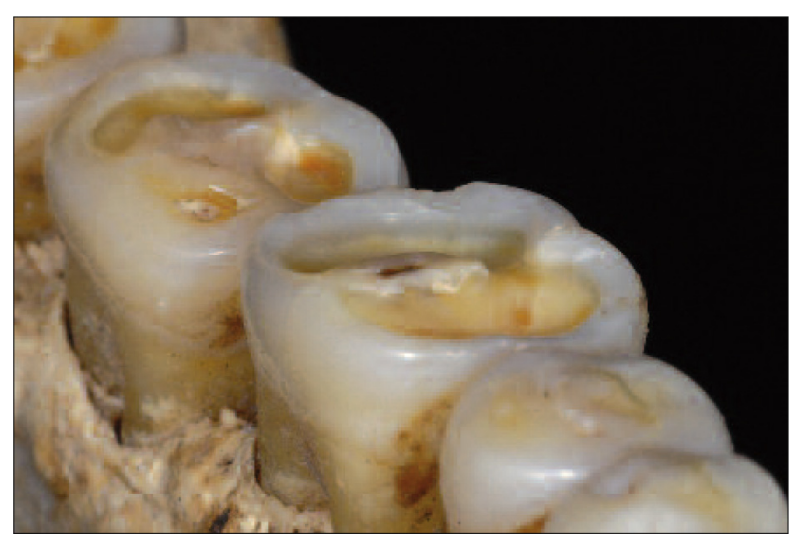

Figure 10

Abrasive occlusal wear afflicted ancient populations. When dentin, which is softer than enamel, is exposed a frank margin appears between them. The enamel becomes smooth and glossy with rounded edges. (Coll. Sains-en-Gohelle, 7-15 s.)

ous eruption of teeth to compensate for loss of vertical dimension from abrasion, modification of the occlusal plane from helicoidal wear, and development of a labidodontal occlusion from one that had initially been psalidodontal $^{9,15,21,23}$. These physiological adaptations primarily associated with function and ontogenesis can still be found in contemporary industrialized populations but in manifestations that are much less pronounced. Today, even though limited in extent, threebody abrasive wear is physiological when it is a corollary of ageing and is a response to an individual's diet. It produces wear facets that grow more extensive as the individual grows older. In posterior segments of the arch two types of facets are present, working and non-working, which are both results of function ${ }^{48}$. They form during different cycles of mastication, guiding them reciprocally ${ }^{26}$. When there are many of these facets and they are distributed widely throughout the arches, dentists must evaluate all wear surfaces that engage equivalent areas in the antagonistic arch during maximum intercuspation when they are planning restorations because such wear is sure to affect the filling material.

When wear is localized, particularly buccally at the necks of teeth, it is usually produced by over-zealous brushing where abrasive particles in the dentifrice constitute the third party interposed between brush and tooth surface. In some cases of wear exacerbated by acid activity the iatrogenic action of brushing can expose dentin of roots (fig. 11). If this activity persists the gingiva can suffer from aggression showing ulceration and recession especially in an environment of poor oral hygiene. Lesions that are broad or notched form in this exposed dentin (fig. 12) and frequently become hypersensitive ${ }^{24}$.

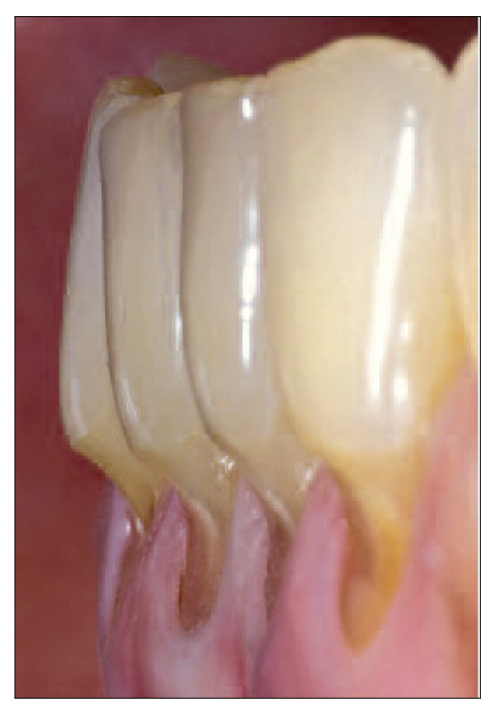

Figure 11

latrogenic wear caused by over-zealous brushing of a 60 year-old female. The softness of the dentin in the root area abraded by a horizontal brushing force has created an abrupt cuneiform appearance. 

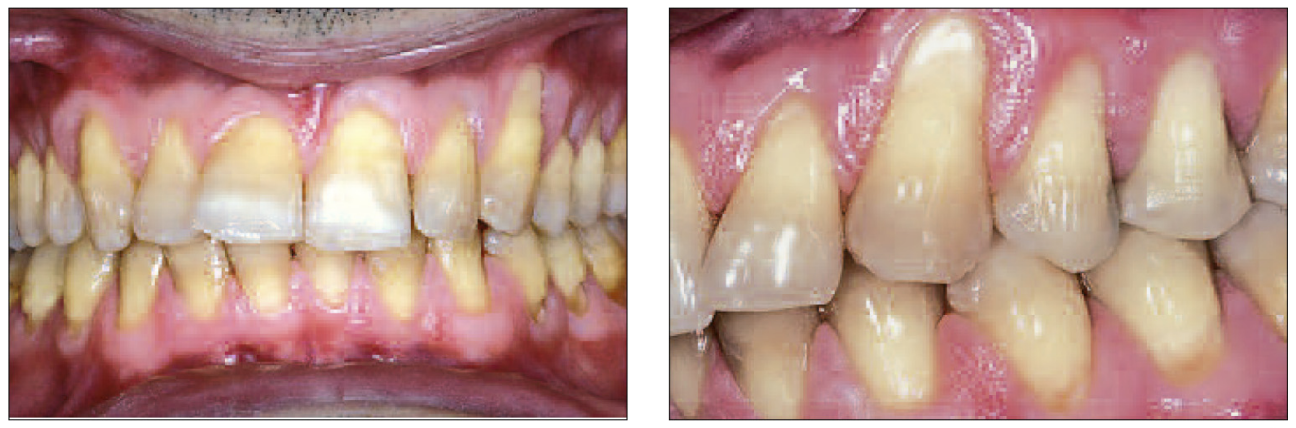

a

Figures 12 and $b$

The mesio-distal axial inclination and the apical extent of the wear lesions affecting the upper canines and premolars are not identical on right and left sides because the right-handedness of the brusher imparts more intensity to the left side that it does to the right, confirming the abrasive etiology.

\section{3 - ADHESIVE WEAR}

This mechanism, essentially occurring with metal and composite restorations, can occur when two bodies under strong pressure slide against each other.

From a tribological point of view, surface asperities that interact with each other undergo a plastic deformation and can unite with each other in localized areas by a process analogous to cold welding. Varying amounts of material are transferred in this way from one surface to the other in amounts that depend on the distance between the materials, their rugosity, the pressure, the temperature or the environment ${ }^{56}$. This accretion of transferred substance can break off if the amplitude of mandibular movement increases but not necessarily along the line of he original fusion (fig. 13). If this mass interposes itself between the two bodies, a three-body abrasion process begins. In the oral cavity,

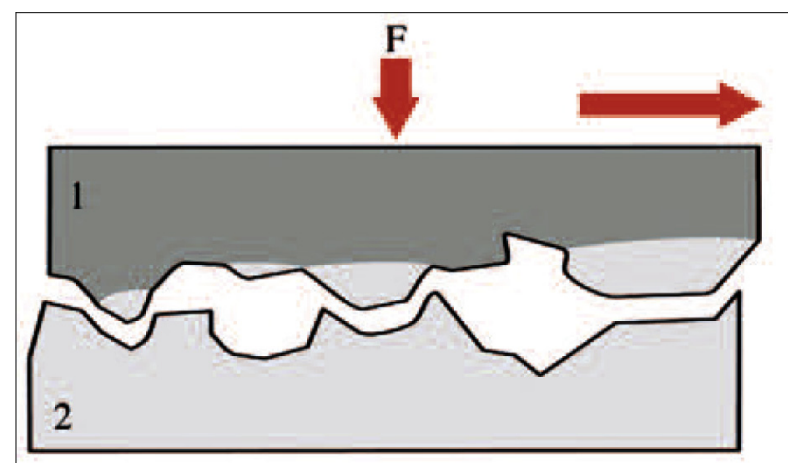

Figure 13

Schematic presentation of adhesive wear.

parafunctions of grinding or clinching are theoretically capable of producing this type of wear.

Actually, in vitro two-body friction tests have demonstrated a transfer of material to enamel (or an analog of enamel) from restorative materials like amalgam $^{47}$ gold $^{20}$, and some composites under high pressure ${ }^{44}$.

In the oral cavity, however, adhesive wear is limited by the lubricating action of saliva that reduces the 
coefficient of friction. Moreover, three-body abrasion provoked by a bolus of food has the tendency to remove the fine covering of the displaced material.

\section{4 - FATIGUE WEAR}

When a surface subjected to strong pressure slides along another surface, a compression zone is created ahead of the movement and a tension zone develops behind it. These deformations that affect the surface molecules can spread to the sub-surface causing ruptures in inter-molecular liaisons. Depending upon the nature of the

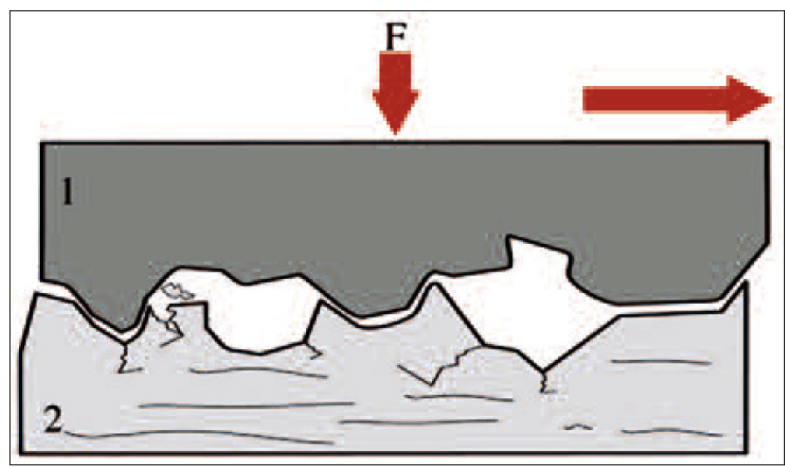

Figure 14

Schematic presentation of fatigue wear.

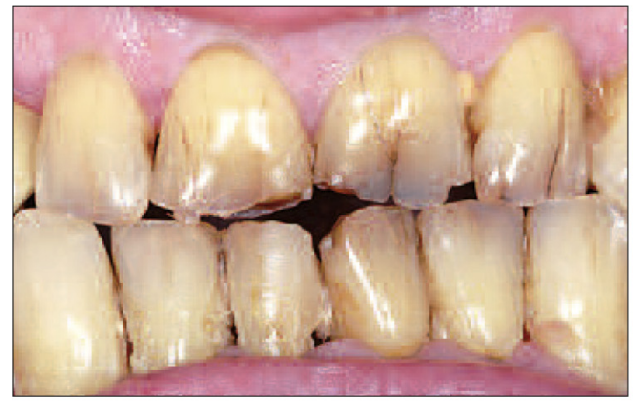

a material these micro-cracks can then spread in repeating cycles in the damaged sub-surface. When this fracture propagation reaches the surface relatively large portions of the material may break off and interpose themselves between the two sliding bodies changing the situation into a threebody mechanism (fig. 14). In general, surface delamination is caused by interactions between the modalities of adhesion, abrasion, and fatigue ${ }^{56}$. In the oral cavity, fatigue wear can appear on some sectors of enamel contact subjected to strong pressure not related to mastication (fig. 15). Enamel's high degree of calcification makes it harder than dentin but its high modulus of elasticity and its low elastic limit put it at greater risk of fracture. However, its prismatic organization in humans tends to block the propagation of these microcracks $^{31,50}$ that occur least frequently

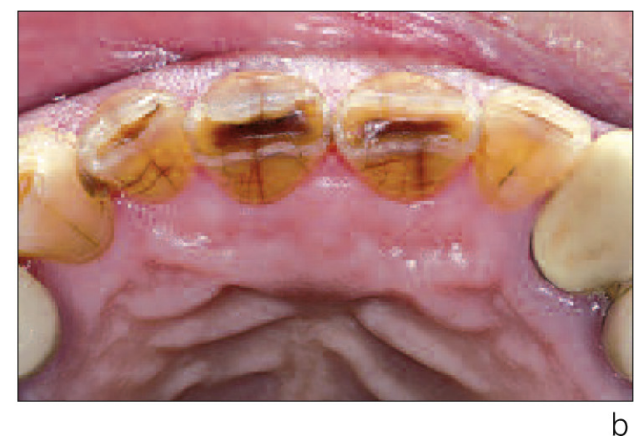

Figures $15 a$ and $b$

Fatigue wear of enamel in an 82 year-old male who had an oral habit. When this produced micro-cracks that reached the surface, fragments of material broke off and dispersed themselves between the teeth. 
occlusally where the prisms are perpendicular to the surface and the calcification is maximal ${ }^{12,}{ }^{53}$. When they do begin to form, enamel microcracks initially provoke delamination of inter-prismatic substance and later the prisms themselves ${ }^{52}$ without being able to pass into the dentin because of the barrier action of the dentinoenamel junction that dissipates these constraints ${ }^{41}$. In certain situations fissuring of enamel or fracture is more likely, for endodontically treated teeth or for teeth with unfavorably shaped

\section{5 - CORROSIVE WEAR (EROSION)}

Corrosion, strictly speaking, is not a wear modality. It occurs when a chemical attack of acid or chelation breaks inter-molecular bonds of dental tissues or restorative materials, making it possible for other wear mechanisms, notably attrition during parafunctional activity during waking hours or sleep, occlusal abrasion, and cervical iatrogenic abrasion stemming from tooth brushing to operate ${ }^{16}$. Surface molecules are then swept away and the newly exposed surface is immediately subjected to assault from the corrosive environment (fig. 16). This variety of wear, virtually unknown in more primitive populations of the past $^{12}$ is becoming increasingly prevalent because of dietary changes, especially in young people ${ }^{39,43}$. The corrosive agents implicated in the process are either extrinsic or intrinsic in origin, from non-bacterial sources ${ }^{30}$.

The principal extrinsic agents are derived from foodstuffs and chemical elements in the environment. They consist, essentially, of sodas, citric crowns, for example, and especially in patients who have day time parafunctions or sleep bruxism ${ }^{10}$.

The notion of fatigue is also essential to the theory of dental flection causing superficial fragmentation of cervical enamel, or abfraction. Although a variety of clinical and theoretical theories have been advanced for indirectly justifying the validity of this connection the causal relationship remains speculative ${ }^{7,36}$.

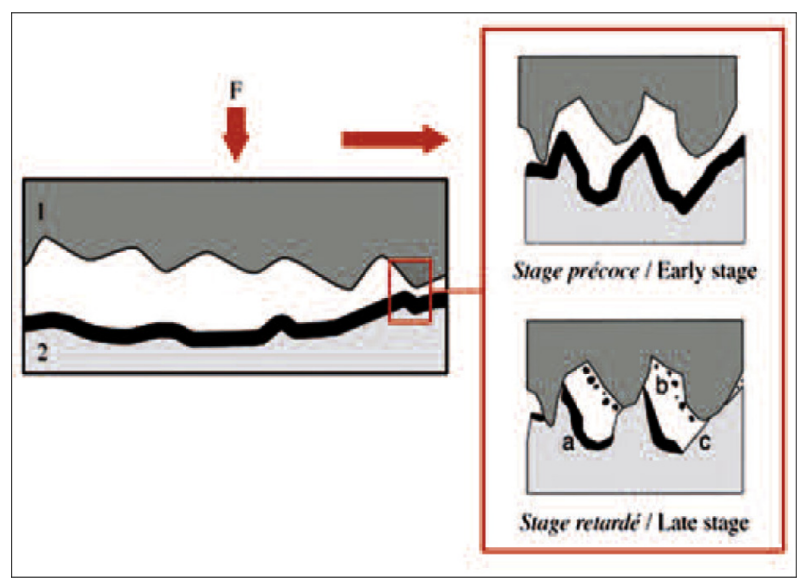

Figure 16

Model of corrosive wear (after Mair, LH. Understanding wear in dentistry. Compend Contin Educ Dent 1999; 20(1): 19-30).

a: corroded areas not affected by surface friction.

$b$ : debris from corroded surfaces immediately after wear occurred.

c: areas just after wear occurred, susceptible to additional corrosion if re-subjected to corrosive agent when surfaces separate.

fruits, pre-mixed alcoholic beverages designed for the adolescent market such as Alcopops, so-called energy drinks, fruit juices, and wines whose 


\begin{tabular}{|l|l|l|}
\hline Type of product & Commercial name & pH \\
\hline \multirow{2}{*}{ Sodas } & Coca-Cola & 2.3 \\
& Coca-Cola light & 2.3 \\
& Fanta Orange & 2.5 \\
& Pepsi & 2.3 \\
& Seven up & 2.3 \\
\hline \multirow{2}{*}{ Sport drinks } & Gatorade & 2.9 \\
& Powerade & 3.3 \\
\hline \multirow{2}{*}{ Energy drinks } & Red Bull & 3.4 \\
& Speed & 2.3 \\
\hline \multirow{2}{*}{ Reference drinks } & Tap water & 7.2 \\
& Lemon juice & 1.8 \\
& Orange juice & 2.8 \\
& Whole milk & 7.0 \\
& Red wine & 3.4 \\
\hline
\end{tabular}

Table 1

pH of some popular drinks lafter Paesani DA. Dental erosion. In: Paesani DA, ed. Bruxism: theory and practice. London: Quintessence publishing, 2010: 149-86). re-calcifying affected tooth surfaces thus limiting deleterious wear activity without being able to prevent it altogether. Dentists should explain these mechanisms to patients and advise them to postpone tooth brushing for at least a half hour after consuming potentially corrosive foodstuffs.

When corrosive wear is active it strongly aggravates brushing-caused cervical and occlusal abrasion, helping to create concave and rounded wear zones $^{4,17}$ (fig. 17). But the contact surfaces of teeth antagonistic to those suffering corrosive wear show no corresponding effect and restorations in them are, in general, unaffected (fig. 18 and 19). During the course of orthodontic treatment, when many patients find it difficult to maintain good oral hygiene and plaque control becomes difficult, carious lesions may develop in association with erosive lesions $^{51}$ (fig. 20).

In today's world, corrosion has become the most prevalent form of dental wear ${ }^{46}$, growing so rapidly that it has become a veritable public health problem. Odontologists in general and orthodontists in particular, accordingly,

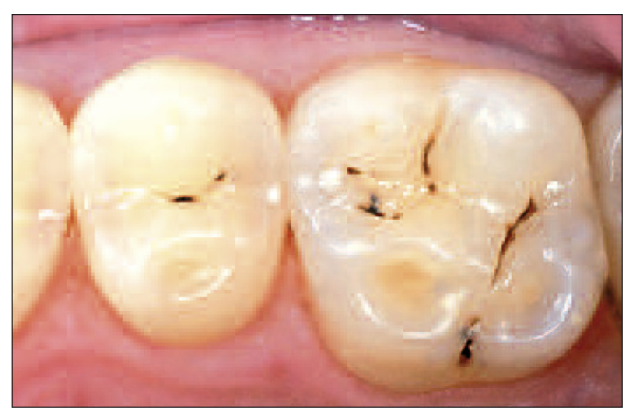

Figure 17

Erosive wear associated with high rate of consumption of cola drinks by a 25 year-old male patient. The wear zones are concave and rounded. 


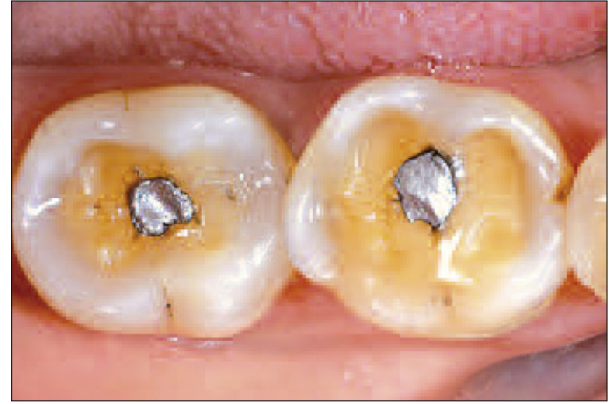

Figure 18

Considerable wear associated with long term excessive consumption of cola soda by a 55 year-old female. The absence of any effect on the amalgam restorations helped the dentist to make a tribo-chemical diagnosis.

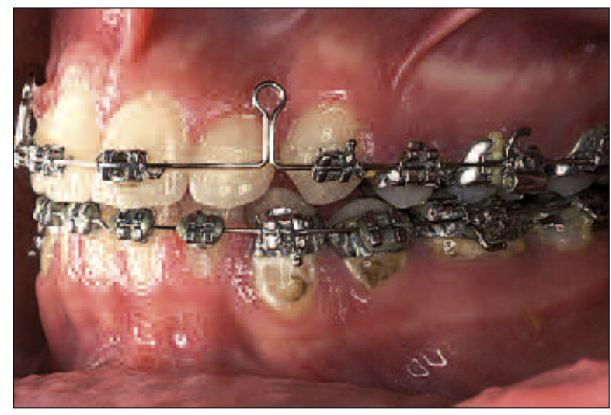

Figure 20

The poor oral hygiene and consequent poor plaque control of this orthodontic patient contributed to the erosive and carious lesions associated with a high consumption of soft drinks.

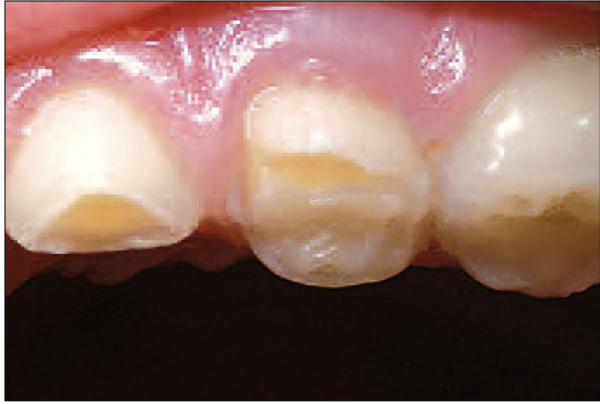

Figure 19

Erosive wear of teeth caused by gastro-esophageal reflux in a young boy. The absence of any erosion of the composite filling in the molar tooth helped the dentist to make a tribo-chemical diagnosis.

have been constrained to search vigilantly for its appearance, to evaluate the risk it presents, and to find ways to prevent this disorder that had not previously been of great concern to them. Whenever they find clinical signs of erosion or indications of the presence of a high risk of erosion, they must take rapid action suitable to the individual situation.

To help them do this, Bartlett, Gans, and Lussi $^{6}$ have proposed a rapid clinical examination called the BEWE, the Basic Erosive Wear Examination (tab. 2 and 3 and fig. 21).

\begin{tabular}{|c|l|}
\hline Degree & \multicolumn{1}{c|}{ Clinical signs } \\
\hline 0 & no loss of tooth structure \\
1 & beginning loss of surface tooth structure \\
$2^{*}$ & pronounced loss of hard tooth structure $;<50 \%$ of surface \\
$3^{*}$ & serious loss of hard tooth structure; $\geq 50 \%$ of surface \\
\hline
\end{tabular}

* Degrees 2 and 3 dentin is often exposed.

Table 2

Examination of the base of dental erosion - evaluation criteria lafter Bartlett DW, Ganss C, Lussi A, Basic Erosive Wear Examination (BEWE); a new scoring system for scientific and clinical needs. Clin Oral Investig 2008; Suppl 1:S65-S68). 


\begin{tabular}{|l|l|l|l|}
\hline \multicolumn{4}{|c|}{ BEWE evaluation } \\
\hline $\begin{array}{l}\text { Highest degree } \\
1^{\text {st }} \text { sextant (17-14) }\end{array}$ & $\begin{array}{l}\text { Highest degree } \\
2^{\text {nd }} \text { sextant (13-23) }\end{array}$ & $\begin{array}{l}\text { Highest degree } \\
3^{\text {rd }} \text { sextant }(24-27)\end{array}$ & \\
\hline $\begin{array}{l}\text { Highest degree } \\
4^{\text {th }} \text { sextant (37-34) }\end{array}$ & $\begin{array}{l}\text { Highest degree } \\
5^{\text {th }} \text { sextant (33-43) }\end{array}$ & $\begin{array}{l}\text { Highest degree } \\
6^{\text {th }} \text { sextant }(44-47)\end{array}$ & Total \\
\hline
\end{tabular}

Table 3

Examination of the base of dental erosion - degrees lafter Bartlett DW, Ganss C, Lussi A, Basic Erosive Wear Examination (BEWE); a new scoring system for scientific and clinical needs. Clin Oral Investig 2008; Suppl 1:S65-S68).

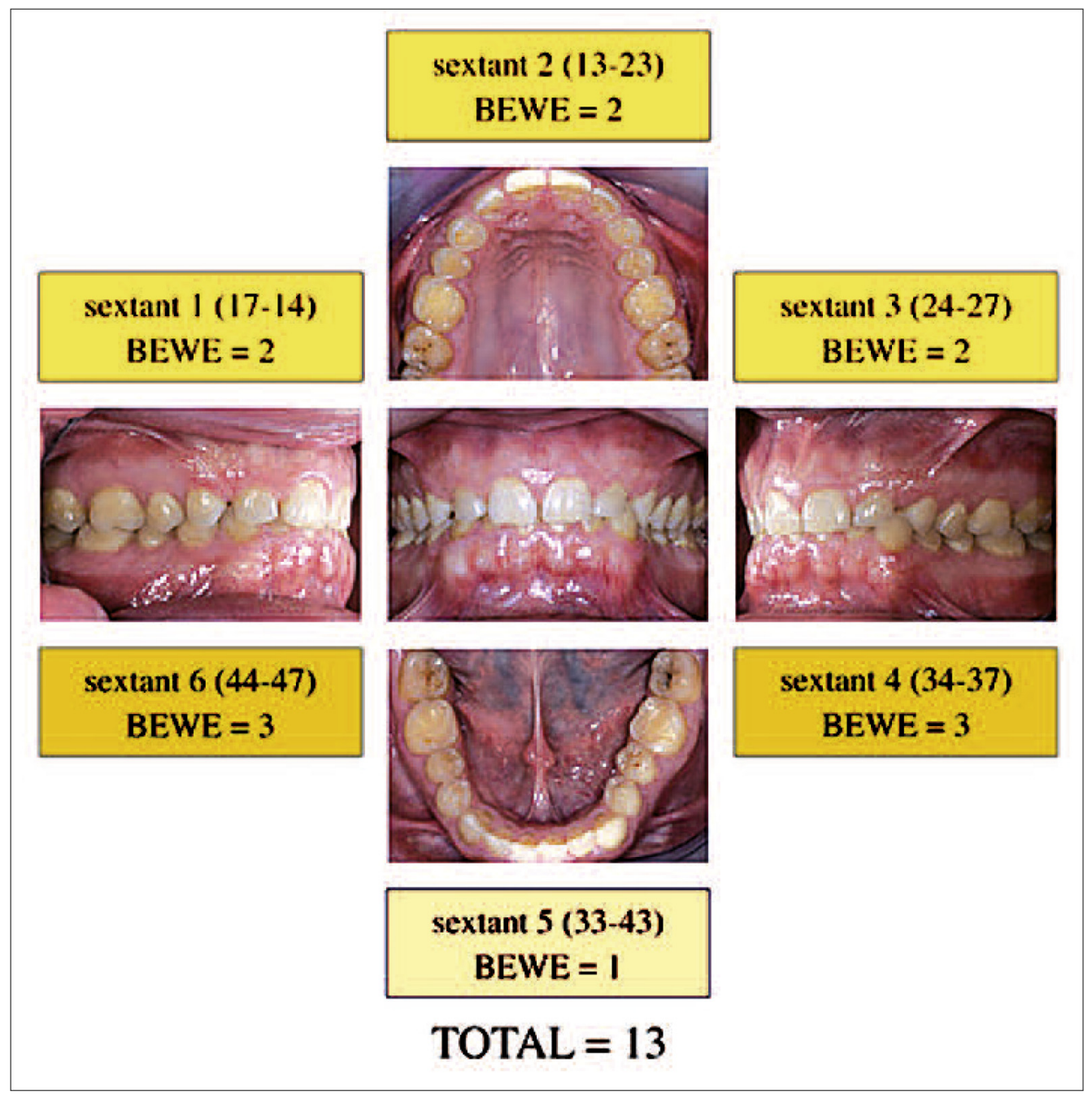

Figure 21

How the BEWE examination is used in assessing a 27 year-old male patient whose teeth are affected by erosive wear caused by a habit (the upper right and left canine teeth are congenitally absent). 


\begin{tabular}{|c|c|c|}
\hline Risk level & Cumulative score of all sextants & Management \\
\hline None & Less than or equal to 2 & $\begin{array}{l}\text { Routine maintenance and observation } \\
\text { Repeat at 3-year intervals }\end{array}$ \\
\hline Low & Between 3 and 8 & $\begin{array}{l}\text { Oral hygiene and dietary assessment, and advice, routine } \\
\text { maintenance and observation } \\
\text { Repeat at 2-year intervals }\end{array}$ \\
\hline Medium & Between 9 and 13 & $\begin{array}{l}\text { Oral hygiene and dietary assessment, and advice, identify } \\
\text { the main aetiological factor(s) for tissue loss and develop } \\
\text { strategies to eliminate respective impacts } \\
\text { Consider fluoridation measures or other strategies to } \\
\text { increase the resistance of tooth surfaces } \\
\text { Ideally, avoid the placement of restorations and monitor erosive } \\
\text { wear with study casts, photographs, or silicone impressions } \\
\text { Repeat at 6-12-month intervals }\end{array}$ \\
\hline
\end{tabular}

Table 4

Risk groups and suggestions for management. No specific recommendations have been made because expert opinions are widely divergent on certain points (after Bartlett DW, Ganss C, Lussi A, Basic Erosive Wear Examination (BEWE); a new scoring system for scientific and clinical needs. Clin Oral Investig 2008; Suppl 1:S65-S68).

Examiners check the buccal, occlusal, and lingual surfaces of all teeth except the third molars to discern and identify lesions. Then they classify them in one of the four degrees of severity, noting the highest value for each sextant. The sum of these values defines the degree of severity of the lesions caused by acid attack and guides dentists in treating patients

\section{6 - CONCLUSION}

A number of physical and chemical mechanisms, which interact with each and helping them improve their oral health behavior (tab. 4). It should be noted that in addition to making general behavioral recommendations dentists can consider suggesting the use of new mouth wash products containing tin chloride and fluorides that have shown encouraging results $^{18}$.

other in most cases, are implicated in the development of dental wear. 
Using tribology, which is the science of interacting surfaces in relative motion and some recently acquired revelations of the science of materials, dentists can now describe the mechanisms of wear systematically, thus improving their understanding of the disorder. The wide prevalence of wear lesions associated with consumption of certain foodstuffs and acidic beverages, especially by young people, is a matter of concern for dental care- givers. It is, therefore, important for dentists in general and orthodontists in particular to fulfill their roles of emphasizing prevention for their patients and the general public and in detecting certain wear patterns that are provoked by noxious habits and over eager and misdirected tooth brushing. They must also be conspicuous promoters of good general and oral health behavior.

\section{REFERENCES}

1. Abe S, Yamaguchi T, Rompré PH, De Grandmont $P$, Chen YJ, Lavigne GJ. Tooth wear in young subjects : a discriminator between sleep bruxers and controls? Int J Prosthodont 2009;22(4):342-50.

2. Abebe M, Appl FC. Theoretical analysis of the basic mechanics of abrasive processes. Part 1: general model. Wear 1988;126:251-66.

3. Addy M, Shellis RP. Interaction between attrition, abrasion and erosion in tooth wear. In: Lussi A, ed. Dental erosion. Monogr Oral Sci. Bassel: Karger, 2006;20:17-31.

4. Bacon W, Canal P, Walter B. Reconnaître les érosions coronaires : atlas des principales formes cliniques. Rev Orthop Dento Faciale 2007;41:333-47.

5. Barbour ME, Rees GD. The role of erosion, abrasion and attrition in tooth wear. J Clin Dent 2006;17(4):88-93.

6. Bartlett DW, Ganss C, Lussi A. Basic Erosive Wear Examination (BEWE): a new scoring system for scientific and clinical needs. Clin Oral Investig 2008;Suppl 1:S65-S68.

7. Bartlett DW, Shah P. A critical review of non-carious cervical (wear) lesions and the role of abfraction, erosion, and abrasion. J Dent Res 2006;85(4):306-312.

8. Begg PR. Stone age man's dentition. Am J Orthod Dentofac Orthop 1954;40:298312;373-83;462-75;517-31.

9. Brace CL. Occlusion to the anthropological eye. In: Mc Namara JA, ed. The biology of occlusal development. Monograph No.7, craniofacial growth series, center for human growth and development. University of Michigan, Ann Arbor, Michigan, 1977:179-209.

10. Brocard D, d'Incau E, Laluque JF. Longitudinal cracks and fractures: risk factors. Rev Odont Stomat 2009;38:265-76.

11. Brocard D, Laluque JF, Knellesen C. La gestion du bruxisme. Paris : Quintessence International, 2008.

12. Cuy JL, Mann AB, Livi KJ, Teaford MF, Weihs TP. Nanoindentation mapping of the mechanical properties of human molar tooth enamel. Arch Oral Biol 2002;47(4):281-91.

13. Dahlberg AA, Kinzey W. Etude microscopique de l'abrasion et de l'attrition sur la surface des dents. Bull Group Int Rech Sci Stomat 1962;5:242-51.

14. DeLong R. Intra-oral restorative materials wear: rethinking the current approaches: how to measure wear. Dent Mater 2006;22(8):702-11.

15. d'Incau E. Approche anthropologique de I'usure dentaire. Cah Prothèse 2004;126:1932.

16. Ganss C. Definition of erosion and links to tooth wear. In: Lussi A, ed. Dental erosion. Monogr Oral Sci. Bassel: Karger, 2006;20:9-16. 
17. Ganss C, Lussi A. Diagnosis of erosive tooth wear. In: Lussi A, ed. Dental erosion. Monogr Oral Sci. Bassel: Karger, 2006;20:32-43.

18. Ganss C, Neutard L, von Hinckeldey J, Klimek J, Schlueter N. Efficacy of a Tin/fluoride rinse: a randomized in situ trial on erosion. J Dent Res 2010;89(11):1214-8.

19. Grippo JO, Simring M, Schreiner S. Attrition, abrasion, corrosion and abfraction revisited. A new perspective on tooth surface lesions. J Am Dent Assoc 2004;135(8):1109-18.

20. Hacker $\mathrm{CH}$, Wagner WC, Razzoog ME. An in vitro investigation of the wear of enamel on porcelain and gold in saliva. J Prosthet Dent 1996;75(1):14-17.

21. Kaifu Y. Edge-to-edge bite and tooth wear. Bull Natn Sci Mus Tokyo D 1996;22:45-54.

22. Kaifu Y. Was extensive tooth wear normal in ours ancestors?: a preliminary examination in the genus Homo. Anthropol Sci 2000;108(4):371-85.

23. Kaifu Y, Kasai K, Townsend GC, Richards LC. Tooth wear and the design of the human dentition: a perspective from evolutionary medicine. Am J Phys Anthropol 2003;Suppl $37: 47-61$.

24. Kaleka R, Saporta S, Bouter D, Bonte E. Lésions cervicales d'usure (LCU) : étiopathogénie. Réalités Cliniques $2001 ; 12(4): 367-85$.

25. Kieser JA, Dennison KJ, Kaidonis JA, Huang D, Herbison PGP, Tayles NG. Patterns of dental wear in the early Maori dentition. Int J Osteoarchaeol 2001;11:206-17.

26. Kim SK, Kim KN, Chang IT, Heo SJ. A study of the effects of chewing patterns on occlusal wear. J Oral Rehabil 2001;28(11):1048-55.

27. Lambrechts P, Goovaerts K, Bharadwaj D, De Munck J, Bergmans L, Peumans M, Van Meerbeek B. Degradation of tooth structure and restorative materials: a review. Wear 2006;261:980-6.

28. Lasfargues JJ, Colon P. Odontologie conservatrice et restauratrice. Tome 1 : une approche médicale globale. Rueil-Malmaison : Cdp, 2009:221-55.

29. Lewis R, Dwyer-Joyce RS. Wear of human teeth: a tribological perspective. Proc I Mec E, Part J: J Engineering Tribology 2005;219(1):1-18.

30. Lussi A, Jaeggi T. Erosion-diagnosis and risk factors. Clin Oral Investig 2008;12(Suppl 1):S5-S13.

31. Maas MC. Enamel structure and microwear: an experimental study of the response of enamel to shearing force. Am J Phys Anthropol 1991;85(1):31-49.

32. Mair LH. Wear in dentistry. Current terminology. J Dent 1992;20(3):140-4.

33. Mair LH, Stolarski TA, Vowles RW, Lloyd CH. Wear: mechanisms, manifestations and measurement. Report of a workshop. J Dent 1996;24(1-2):141-8.

34. Mair LH. Understanding wear in dentistry. Compend Contin Educ Dent 1999;20(1):1930.

35. Mair LH. Wear in the mouth : the tribological dimension. In: Addy M, Edgar WM, Embery G, Orchardson R, eds. Tooth wear and sensitivity. London: Martin Dunitz, 2000:181-8.

36. Michael JA, Townsend GC, Greenwood LF, Kaidonis JA. Abfraction: separing fact from fiction. Australian Dent J 2009;54(1):2-8.

37. Milosevic A. Tooth wear: an aetiological and diagnostic problem. Eur J Prosthodont Rest Dent 1993;1(4):173-8.

38. Paesani DA. Tooth wear. In: Paesani DA, ed. Bruxism: theory and practice. London: Quintessence publishing, 2010:123-48.

39. Paesani DA. Dental erosion. In: Paesani DA, ed. Bruxism: theory and practice. London: Quintessence publishing, 2010:149-86.

40. Pickles MJ. Tooth wear. In: Duckworth RM, ed. The teeth and their environment. Monogr Oral Sci. Bassel: Karger, 2006;19: 86-104.

41. Roy S, Basu B. Mechanical and tribological characterization of human tooth. Mater Charact 2008:59:747-56.

42. Seligman DA, Pullinger AG. The degree to wich dental attrition in modern society is a function of age and of canine contact. J Orofac Pain 1995;9(3):266-75. 
43. Smith BGN, Knight JK. A comparison of patterns of tooth wear with aetiological factors. Br Dent J 1984;157:16-9.

44. Söderholm KJ, Richards ND. Wear resistance of composites: a solved problem? Gen Dent 1998:46(3):256-63.

45. Turssi CP, de Moraes Purquerio B, Serra MC. Wear of dental resin composites: insights into underlying processes and assessment methods-a review. J Biomed Mater Res Part B: Appl Biomater, 2003;65B:280-5.

46. Wang $X$, Lussi A. Assessment and management of dental erosion. Dent Clin North Am 2010;54(3):565-78.

47. Wassell RW, Mc Cabe JFM, Walls AWG. A two-body frictional wear test. J Dent Res $1994 ; 73(9): 1546-53$.

48. Woda A, Gourdon AM, Faraj M. Occlusal contacts and tooth wear. J Prosthet Dent 1987;57(1):85-93.

49. Wolpoff M. Interstitial wear. Am J Phys Anthrop 1971;34(2):205-27.

50. Xu HHK, Smith DT, Jahanmir S, Romberg E, Kelly JR, Thompson VP, Rekow ED. Indentation damage and mechanical properties of human enamel and dentin. J Dent Res 1998;77(3):472-80.

51. Yip HHY, Wong RWK, Hägg U. Complications of orthodontic treatment: are soft drinks a risk factor? World J Orthod 2009;10(1):33-40.

52. Zheng J, Zhou ZR. Study of in vitro wear of human tooth enamel. Tribology Letters 2007;26(2):181-9.

53. Zheng J, Zhou ZR, Zhang J, Li H, Yu HY. On the friction and wear behaviour of human tooth enamel and dentin. Wear 2003;255:967-74.

54. Zhou ZR, Zheng J. Oral tribology. Proc I Mec E, Part J: J Engineering Tribology 2006;220(8):739-54.

55. Zhou ZR, Zheng J. Tribology of dental materials: a review. J Phys D: Appl Phys 2008;41:113001, 22p.

56. Zum Gahr KH. Classification of wear processes. In: Microstructure and wear of materials. Amsterdam: Elsevier, 1987:80-131.

57. Zum Gahr KH. Wear by hard particles. Tribology Int 1998;31(10):587-96.

\section{ACKNOWLEDGEMENTS}

The authors acknowledge SARL ArchéoSphère (Bordeaux) for free access to the collection Sains-en-Gohelle (fig. 3 and fig. 10). 